\title{
Organizational Factors and Competitiveness: A Case Study of Medium and Large Manufacturing Enterprises in Rwanda
}

\section{Rusibana Claude}

Department of Finance and Accounting, Mount Kenya University, Rwanda

\begin{abstract}
The manufacturing organizations or enterprises present greater opportunities for sustained growth, employment and poverty reduction. They play a key role in driving sustainable economic growth and job creation. In literature, it has long been recognized that internal and external organizational factors have contributed to the organizational competitiveness. To date, empirical literature has demonstrated that several scholars have identified a number of organizational factors. the external factors have been identified as political, technological, market, competitors' action, social and cultural are beyond the control of a given origination and internal factors were identified as innovation, entrepreneurship culture, leadership, organizational resources, size and market orientation can be controlled. However, the researcher discovered that in Rwanda, there is no study that attempted to test the direct relationship between organizational factors (namely leadership, market orientation and organizational resources) and competitiveness of manufacturing enterprises. There is no general consensus on most important internal organizational factors influencing organizational competitiveness. There is no specific research by scholars which attempted to determine organizational factors that is related to competitiveness of medium and large manufacturing enterprises in Rwanda. Therefore, the researcher assessed the relationship between leadership, market orientation and organizational resource factors and competitiveness to respond to the existing mentioned gap. The research aimed at assessing the any correlation between organizational factors and competitiveness of medium and large manufacturing enterprises. The research used both correlation and regression analysis technique. The research design employed was survey. The target population was the middle managers of the medium and large manufacturing enterprises amounted to 123. Using Solvin formula 91 respondents were selected in manufacturing enterprises. to ensure the validity and reliability of the research instruments, the test and pre-test of the questionnaire was conducted. The data collected were analyzed using SPSS. The findings revealed that, the $65.9 \%$ of the assessed manufacturing enterprises were not competitive and that, organizational factors have moderately positive effect towards organizational competitiveness. The regression analysis results concluded that market orientation $(\beta=0.425$ with $P$-value of 0.002$)$ has a significant positive effect towards organizational competitiveness while leadership $(=0.51$ with $P$-value of 0.860$)$; Human resource $(\beta=0.199$ with $P$-value of 0.851 ); Asset Tangibility ( $\beta=0.0252$ with $P$-value of 0.970$)$; Financial resource capability $(\beta=0.196$ with $P$-value of 0.995). The policy makers, enterprises and future researchers were recommended to re-assess the capacity gaps of business leaders and business managers for capacity building to -enhance competitiveness. The business leaders need to focus and promote staff motivation, creativity and innovation for better performance because the leaders are autocratic and show little involvement of employees. The enterprise business leaders should recruit employees on competency basis rather than relationship. The Enterprises should award employees' talents, creativity and innovation to increase the quality of production and be able to adapt to the changing market needs.
\end{abstract}

Keywords: Organizational factors; Manufacturing enterprises; Economic growth

\section{Introduction}

The manufacturing organizations or enterprises present greater opportunities for sustained growth, employment and poverty reduction [1]. They play a key role in driving sustainable economic growth and job creation [2]. They are key resource consumption and they generate revenue for the society by importing in foreign currencies from exporting goods [3].

In Africa, the economic contribution of the manufacturing sector is still low, the export and GDP contribution share has been falling and characterized by commodity exports. The manufacturing in Africa is heavily dependent on resource-based manufactures; dominated by small firms most of which are informal with weak technological capabilities and their performance varies from country to another [1]. The SME growth is reported to have been constrained by market imperfections and institutional failures; poor business environment and limited access to finance [4].

In East Africa, the manufacturing sector GDP contribution varies with countries. For example, in 2013, the manufacturing sector in
Kenya contributed $11.7 \%$ of the GDP; $10.6 \%$ in Uganda in 2013; 7.4\% in Tanzania and 5.1\% in Rwanda in 2014 (www.africaeconomic outlook.org).

In Rwanda, the industrial sector has remained stagnant in the past decade and it is composed of manufacturing, mining, electricity, water \& waste management and construction and it is expected to account for $26 \%$ of the GDP by 2020 [5,6]. Currently, it accounts for $0.5 \%$ of the GDP growth rate and $14 \%$ of the GDP at current market price (xUSD). Rwanda has a total of 154,236 industrial establishments, of which $7 \%$

*Corresponding author: Rusibana Claude, Department of Finance and Accounting, Mount Kenya University, Rwanda, Tel: +250788825254; E-mail: crusibana@mku.ac.ke

Received September 08, 2018; Accepted October 11, 2018; Published October 21, 2018

Citation: Claude R (2018) Organizational Factors and Competitiveness: A Case Study of Medium and Large Manufacturing Enterprises in Rwanda. J Bus Fin Aff 7 : 354. doi: 10.4172/2167-0234.1000354

Copyright: $@ 2018$ Claude R, This is an open-access article distributed under the terms of the Creative Commons Attribution License, which permits unrestricted use, distribution, and reproduction in any medium, provided the original author and source are credited. 
(10742) are in manufacturing sector. Out of the 10742 manufacturing enterprises, 9127 (85\%) are micro, 1497 (13.9\%) are small, 70 (0.7\%) are medium and $48(0.4 \%)$ are large manufacturing enterprises [7]. The manufacturing enterprises contributed $0.3 \%$ of the total GDP growth rate and employees $1.9 \%$ of the total workforce $[8,9]$.

The Rwanda's import has increased by $1.9 \%$ and exports decreased by $10.07 \%$ [10]. Globally, out of 148 countries, Rwanda's competitiveness position seats at the position of $66^{\text {th }}$ of which it was ranked $71^{\text {st }}$ on basic requirements; $96^{\text {th }}$ on efficiency enhancers and the $66^{\text {th }}$ for innovation and sophistication factors of global competitiveness [11].

Like many of the developing countries, Rwandan enterprises operate in an environment that is extremely competitive and have benefited less from free market global economy due to the exportation of commodities with low value. Like any other developing countries, only a small proportion of macro and small firms in Rwanda grow beyond certain threshold, due mainly to lack of specific management and/or marketing skills, lack of trust in society and lack of more and sophisticated medium sized enterprises [12].

The industrial growth and competitiveness is constrained by low productivity, low industry base dominated by micro and small enterprises, high transport costs, high cost of financing, high energy costs, limited industrial research and development capacities and low purchasing power governance gaps [13], shortage of industrial skills and many of which are compounded by small, fragmented, and underdeveloped markets [14] and low integration and clustering between large and small firms [12]. The underlying industrial competitiveness challenges of Rwanda's requires further investigation and avail data for the enterprises thus, the research problem.

In literature, it has long been recognized that organizational competitiveness might be influenced by both internal and external factors. To date, empirical literature has demonstrated that several scholars have identified a number of organizational factors. the external factors have been identified as political, technological, market, competitors' action, social and cultural are beyond the control of a given origination [15] and internal factors were identified as innovation, entrepreneurship culture, leadership, resources, size and market orientation can be controlled. Most of which were studied as moderating factors towards organizational performance and/ or competitiveness. The researcher observed that:

- In Rwanda, there is no study that attempted to test the direct relationship between organizational factors (leadership, market orientation and organizational resources and market orientation) and competitiveness of manufacturing enterprises

- There is no general consensus on most important internal organizational factors influencing organizational competitiveness

- There is no specific research by scholars which attempted to determine organizational factors that is related to competitiveness of medium and large manufacturing enterprises in Rwanda.

In this regard, this research was commissioned to assess the relation between leadership, market orientation and organizational resources factors and competitiveness

\section{The Objective of the Study}

The purpose of the study is to determine if there is any significant positive relationship between organizational factors and competitiveness of Medium and Large Manufacturing Enterprises in Rwanda.

The following are the specific objectives of the study:

i. To establish the relationship between organizational leadership and competitiveness of Medium and Large manufacturing enterprises in Rwanda.

ii. To establish the relationship between organizational market orientation and competitiveness of Medium and Large manufacturing enterprises in Rwanda.

iii. To establish the relationship between the Organizational resources and competitiveness of Medium and Large manufacturing enterprises in Rwanda.

\section{Research hypothesis}

The overall hypothesis of this study is that, organizational factors have a significant positive effect to competitiveness of the Rwandan medium and large manufacturing enterprises. The specific hypotheses of the study are bulleted below:

H01: Organizational Leadership has a significant positive effect on organizational competitiveness

H02: Market orientation has a significant positive effect on organizational competitiveness

H03: Organizational human Resources has a significant positive effect on organizational competitiveness

H04: Organizational asset tangibility has a positive significant relationship on organizational competitiveness

H05: Organizational financial capability has a positive significant relationship on organizational competitiveness

\section{Literature Review}

\section{Organizational factors}

In context of this study, organizations here referred to, are medium and large manufacturing enterprises that produce products for the market. The manufacturing sector is a component of industry that presents greater opportunities for sustained growth, employment and poverty reduction. The Manufacturing enterprises refers to those organizations that, physically or chemically transformations materials, subsistence or components into new products [1]. In literature, Organizational competitiveness factors are subdivided into internal and external internal factors [16] and their role has been recognized in shaping competiveness [17]. These factors has been conceived as environmental or situational issues that affect an organizations' strategic effectiveness [18]. On the other hand, organizational factors were described as the mould of characters of an organization important enough to shape the organizational readiness for change [19].

The internal factors remain to be the main focus of this study. In literature, the identified internal organizational factors include: organizational compliance, marketing, productivity location and business retaliations [20], entrepreneurship culture, structure [21], Knowledge, behavior [22], design strategy, coordination, structure and decision making frameworks [23], management and communication culture [24] management structure, size, age and financial ability [18], Industry type-low, medium or high tech and product innovation [25], Integration, process optimization, access to information, skills and organizational climate, organizational partnerships, employee 
participation and trust, strategy and risk taking, leadership and management support, resources and information system [19], communication, commitment and trust [26], innovation climate and incentives [27], core competencies and capabilities [28], process design [29] and market orientation [30].

\section{Competitiveness}

In literature, competitiveness has been described as multidimensional and relative concept [31], that changes with context and time. It embraces different approaches, from classical theories of mercantilism, which introduced the notion of trade rivalry between nations, to absolute advantages of notions, the theories of competitive and comparative advantages and up to neoclassical critiques of international competitiveness of countries [32]. It constitutes a major economic objective in the current context of globalization, rapid technical change and frequently invoked by policy makers worldwide [33]. The competitiveness defines economic strength of an entity with respect to its competitor and it has the country, industrial and enterprise perspectives [26]. There is no agreed definition of national competitiveness [34]. However, the WEF, 2013 refers to national competitiveness as a set of institutions, policies and factors that determines the level of productivity of country [11]. The Chiang [34] defined national competitiveness as a measure of relative ability of a nation to create and maintain an environment in which enterprises can competent so that the level of prosperity can be improved. According to Wilfred [18] organizational competitiveness refers to its ability to create more economic value than other competing firms. On the other hand, enterprise competitiveness refers to its ability to design [23], produce and/or market products superior to those of offered by competitors, considering the price and non-price product qualities [26]. The organizational competitiveness relates to continuous presence in markets, profit making and the ability to adapt production to demand [35]. The organization is said to be competitive over its rivals, if there are dynamic, able to respond to any changes with versatility, flexibility [21], innovative and able to create economic value than its competitors [18]. The organization that seeks to build competitive advantage has to well mange its core processes and resources -human, operations, technology and financial [26] and strive for low cost leadership. The competitiveness measurement remains paramount. The 12 pillars covering basic requirements, efficiency enhancers, innovation and sophistication are global competitiveness indices have been used to measure competitiveness among factor driven, efficiency and innovation driven economies respectively [11]. The policy makers, an academia and business leaders focuses on microeconomic and macroeconomic factors as key indicators of competiveness [33].

The industrial competitiveness is assessed based on a number of indicators, mainly total productivity, Innovation, market share, profitability [34], finance and investments, ability to export, business environment and entrepreneurship, public administration and sustainability [32], product quality, price, growth rate, and the enterprises' cost leadership ability and overall ability to turn input into output in the most efficient and economic way [18].

\section{Organizational leadership}

In literature, the leadership effect on organizational competitiveness has long been appreciated. Leadership has been described as a complex phenomenon which involves a leader, the follower and a situation. It involves both rational and emotional sides of the human experience. Also, it has been described as every one's business and a process and not a position that requires both science and art [36]. Leadership researchers have defined leadership in many ways. Gerry defined leadership as process of influencing an organization or group within an organization in its efforts to towards achieving goals [37]. Sarah defined leadership as the action of leading a group of people or organization or having the ability to lead [38]. Fielder defined leadership as a process of directing, coordinating the work of group members.

In the face of these expectations, leaders are often measured and described on the basis of their leadership styles and models. The transactional, Transformational [39], situational, continuum, (team leadership styles-2013, www.free-management -ebooks.com (ISBN 978-1-62620-988-6), autocratic, bureaucratic, charismatic, democratic, laissez Faire and task-oriented leadership styles exist. The style relates to specific behavior and influenced by the leaders' personality, traits, character, vision, challenge, interaction with the team and competence [38].

In a highly competitive global market [40] good leaders makes timely decisions, provides direction, cerates plans, gives regular feedback and secures the resources for the followers success [36]. Leaders are expected to have the ability to understand their customers and provide high quality products or effective services [31], plan and allocate resources such as assets, organizational core competencies, knowledge and processes to attain organizational specific goals effectively and efficiently. This consist of effective policies for handling raw-materials, machines, and equipment during the manicuring which lead to low handling cost, reduced $m$ manufacturing cycle time, better control of goods flow, less rejects, and decreased storage requirements [19]. The core capabilities of business leaders and managers are part of competitive advantage to the business. The effective leaders should be skillful [26], and capable to effectively apply strategies and build internal management systems of the organization and better utilize organizational core capabilities to achieve efficiency and become competitive over its competitors [3].

\section{Market orientation}

The market orientation has been conceived as a marketing concept and management strategy that assists in development of marketing knowledge, superior performance, and competitive advantage [30,40]. Market orientation is about market intelligence gathering, intelligence dissemination, and responsiveness to market intelligence. In marketoriented organizations uses inter-functional capabilities to create customer-driven value and they on key constructs of: customer orientation, competitor orientation and inter-functional coordination [30].

Customer orientation is an organizational culture that considers present and potential customer's needs and wants constantly producing value [40]. It involves all the activities related to information generation, information dissemination, appropriate responses to current and future customer needs. It has been viewed as an important strategic orientation of an organization that refers to the sufficient understanding of one's target buyers to be able to create superior value and deliver customer satisfaction [41]. The Nachiappan defined customer satisfaction as customer's evaluation of a product or service with regard to their needs and expectations [31]. For example, customers do not value product features at any price, if price goes high, they will sacrifice value and opt for low price and in return, organizations have been challenged to maintain appropriate level of value at acceptable price [37].

The competitor orientation refers to the ability of an organization to understand the competitor's short term strength, weaknesses and its long term capabilities and strategies to generate competitive advantage in organization for sustained performance [30]. In particular, with 
the increasing competitive rivalry, organizations are required to lower their costs so as to underprice their rivals while offering similar value [37]. On the other hand, inter-functional coordination refers to the coordinated efforts of an organization's resources in creating superior value to customers and to generate cooperation among all departments of the organization to create superior value for customers. This construct of market orientation emphasizes collaborative culture within organization which enables firm's competitive performance and requires involvement of each employee [30].

\section{Organizational resources}

Resources refers to an asset or input to production (tangible and intangible) that an organization owns, controls and utilizes for productivity and competitiveness [28]. Scholars have recognized the importance of internal organizational resources to organizations' competitive position [42]. The organizational tangible resources, namely human, physical, technological, financial and intellectual capital resources as well as the intangible resources such as reputational, regulatory, positional, functional, social and cultural resources are hard to imitate, important and critical in attaining and sustaining organizations' competitiveness [37,43]. The tangible and intangible resources and competences (threshold and core competencies) are strategic capabilities of an organization that is needed for survival and prosperity [37]. In this study, the particular attention was put to the following tangible resources.

Human resource: The human resources are a set of individuals who make up the workforce of an organization. it is one of the most import asset for any organization and a source for competitive advantage in enterprises [15]. It acts as a source of organizational capabilities and intellectual capital [28], they covert other resources like money, machine, methods and materials into products or services [15]. the human resource capability remains key and it refers to the skills and knowledge of employees and other people in an organization's network [37]. The organizations require core competencies for competitiveness and often, there are anchored within the people. The core competencies are required to integrate, build and re-configure resources, capabilities and environment to generate for competitiveness of the organization [28]. The human reliability is an import element of an organization for competitiveness. The human capital reliability is measured by means of performance shaping factors, particularly training, experience, procedures, management, communication and culture.

Assets: The two kinds of assets exist. There are physical (tangible) and non-physical (intangible) assets. the intangible assets, (namely reputational, regulatory, positional, functional, social, cultural [43] and Intellectual capital (brands, patents, business systems and customer base [37] are key elements of organizational competitive advantage and performance. In knowledge-based economy, intellectual capital remains to be a major asset of the organization, the use and deployment of such resources matters atleast as much as the other resources [37].

The physical resources remain to be the main focus of this study. The physical resources (building, machinery, equipment, production materials and technologies) are essential for the organizations' success in presence of uncertainty [43]. The availability and the nature in terms of age, condition, capacity and location determines the usefulness of the such resources [37] and may affect organizational competitiveness.

Size is an organizational variable and determinant of firms' economic and financial behavior that affects organizational performance [44].
Financial resources: The financial resource is the basic resource required and used to acquire other resources. ample funding is indispensable, the financial ability of the organization enables it to acquire modern equipment, technology, land, building and human resources for its operations which leads to being more completive [18]. The financial resources are viewed in terms of capital, cash, debtors and suppliers of money [37]. The finical growth ability of an organization forms a key indicator of its competitiveness [18]. The small and medium enterprises are often constrained financially than large ones and there less likely to access finance [4]. The enterprises find it difficult to access finance. Relative to banks, small firms are considered risky and the information asymmetry problem is more severe among those enterprises. The cost of transaction is often high. In return, small enterprises suffer from financing difficulties in bank-based financing system.

The lack of finance by manufacturing enterprises constrains their productivity, growth and their innovative capacity for sustained performance and competitiveness [45].

In Rwanda, the issue of access and effective management of financial resources remains a challenge for small, medium and large enterprises. Rwanda recognizes the importance of finance for competitiveness of enterprises. Special SME, agriculture, export and manufacturing guarantee funds and funding schemes have been established.

\section{Empirical literature review}

In literature, the relationship between organizational factors and competitiveness has been appreciated. Many of the scholars have identified a number of organizational factors and in some cases, their moderating effect towards organizational performance and firm competitiveness has been studied. For instance:

Wilfred of the European Journal of Business and Management concluded that, firm size, firm age, management structure and financial capability are moderating organizational factors on the relationship between the diversification strategies and competitiveness of Kenya sugar firms [18].

Julian of the International Journal Business Management, analyzed the relationship between organizational factors and quality of production in Malaysia's manufacturing companies [19]. The organizational resources, rewards and recognition structure and information system were the organizational factors. Using a multi-regression analysis technique, with the exception of rewards and recognition structure, a positive relationship between the remaining organizational factors and quality of production was found in Malaysia's manufacturing companies. Yosuke of the international journal of business and management investigated the role of organizational factors in product design development process [23]. The effect of design strategy, interdivision coordination, organizational structures and decision-making frameworks organizational factors on how impact product design process. The research results showed how these factors impact that early stage involvement of design divisions.

Anita of the working paper of Harvard University, identified poor process design, insufficient workspace, lack of integration in the internal supply chains as the organizational factors associated with operational failures in hospital [29]. The research results concluded that organizational factors contributed to operational failures.

Sadegh of the international journal of business and management, explored the effect of organizational factors on collaboration process 
between University and industry in Malaysia [26]. The communication, trust, conflict, leadership and commitment were the organizational factors whose effects on University-Industry collaboration were studied and a positive effect was found. The factors have independent role on success of collaboration. There is interaction between each factor, thus the strength and weakness of each factor have direct or indirect effect on others.

\section{Critical review and research gap identification}

The empirical literature has demonstrated that several scholars identified a number of organizational factors, most of which were studied as moderating factors towards organizational performance and/or competitiveness. The researcher observed that:

- There is no study that attempted to test the direct relationship between organizational factors (leadership and management, firm size, organizational resources \& market orientation) and competitiveness of manufacturing enterprises.

- There is no general consensus on most important organizational factors influencing competitiveness.

- There is no specific research by scholars which attempted to determine organizational factors that is related to competitiveness of Rwandan manufacturing enterprises.

On the basis of such observation, the researcher attempts to generate knowledge and test the relationship between organizational factors and competitiveness among Rwandan manufacturing enterprises.

\section{Conceptual framework}

The conceptual framework focuses on the relationship between organizational factors and competitiveness for manufacturing enterprises in Rwanda. The organizational factors are independent variable whereas competitiveness is the dependent variable. Organizational factors are conceptualized as organizational leadership, resources, size and market orientation as essential factors that influence competitiveness for manufacturing enterprises in Rwanda (Figure 1).

\section{Research Methodology}

\section{Research design}

The researcher used descriptive and correlational survey design. The qualitative and quantitative approaches used to collect secondary and primary data. The four Likert scale survey questionnaires was designed, pre-tested and used to collect quantitative data while interview guide questionnaire was used to collect qualitative data for further analysis. The two approaches complimented each other in eliciting the truth. The relationship and causal effect was analyzed using correlation and regression analysis techniques.

\section{Target population}

The study targeted medium and large formal manufacturing enterprises, registered in Rwanda Development Board (RDB) and other concerned institutions. NISR indicated that the medium manufacturing enterprise in Rwanda count 70 and large manufacturing enterprise count 48 which are equal to 118 enterprises in total [7]. The Table 1 below shows the distribution of target manufacturing enterprise by size and proportion.

\section{The sample size and the sampling procedure}

Sample size: A representative sample reflects the various key aspects of the population. Since it was not known the proportion of

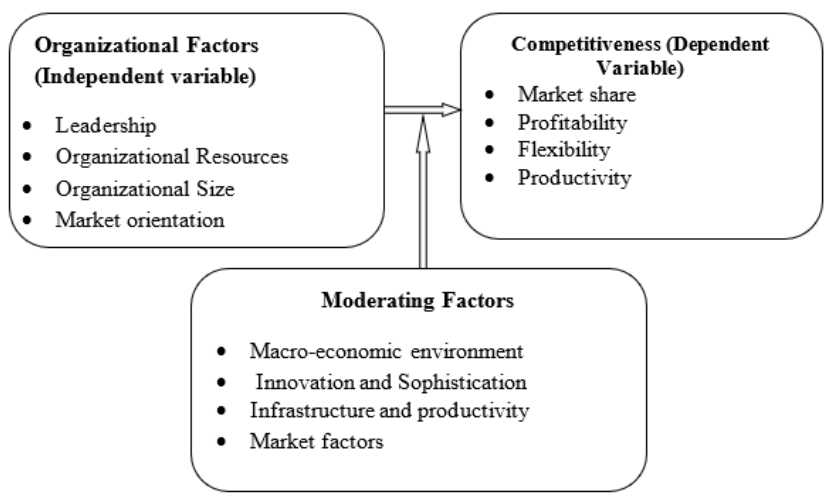

Figure 1: Conceptual framework.

industrial experts, Heads of Key Government Agencies and Ministries will provide the information on the research questions, The SLOVIN's formula will be applied to determine the exact sample size:

$$
n=\frac{N}{1+N\left(e^{2}\right)}
$$

Where; $\mathrm{n}=$ the required sample size; $\mathrm{N}=$ the known population size; and $\mathrm{e}=$ the level of significance, which is $=0.05$. Given a total population of 118 manufacturing enterprises will be extracted into investigated companies; its sample size will be 91 enterprises as calculated as

$$
n=\frac{N}{1+N\left(e^{2}\right)} \frac{118}{1+118(0.05)}=\frac{118}{1.295}=91 \text { plus five concerned }
$$

institutions.

One person per organization answered the questionnaire, totaling to 91 respondents to the Table 1 below indicates the sample size for each stratum.

Sampling procedure and techniques: The research used stratified random (not only used if ministries and agencies are not sampled) sampling in selecting manufacturing enterprises by size in the enterprises which locate in industry sector and other related institutions like Ministries and their agencies. The population was segregated into several mutually exclusive subpopulations or strata herein referred to as manufacturing businesses, and other concerned institutions. The random sampling techniques shall be used. In the random sampling each manufacturing enterprises, the one has an equal chance of being chosen. The key informants were Heads of Key Government Agencies and Ministries.

\section{Data collection instruments}

Data collection refers to the process of collecting primary and secondary information of the targeted population. In this study, primary data was collected using questionnaires techniques, conducting interviews and observing facts on the ground. Secondary data were collected from the online publications and hard documents.

Questionnaire: Kendall and Bucklanda as cited by Rwagasana (2002:63) defined a questionnaire as a group or sequence of questions designed to elicit information upon a subject or sequence of subjects from a key informant indeed a questionnaire will be designed and pretested before submitting the sampled enterprises. In this instrument, the data was collected using self-administered structured four-point likert scale questionnaire as the research instrument. 
Interviews: According to Frankfort-Nadunias the personal interview is a face to face, interpersonal role situation in which an interviewer asks respondents questions designed to elicit answers pertinent to research hypothesis [46]. The face to face discussions were carried out between the interviewer and the interviewees and the method sets a mood to acquire accurate information. The interview guide containing both closed and open-ended questions was used for data collection.

\section{Validity of instrument}

The validity of instruments was measured using Content Validity Index. Two raters/experts in the field of study will be used to rate the content in the questionnaire. These experts will also assist in assessing the phrasing of the questions to avoid ambiguity. The researcher will view each statement with the help of experts and assess the extent to which the questions will be related to the topic of the study. The researcher will compile the responses from raters and will compute the Content Validity Index (CVI). The estimation for validity is 0.75 and above, meaning that any value below it would make the instruments invalid. Therefore, the content validity calculated as follows:

$$
C V I=\frac{\text { Number of declared } \text { valid }}{\text { Total number of items }}
$$

Thus, CVI $=54 / 62=0.87$

\section{Reliability statistics}

Cronbach's alpha Coefficient was used to measure the reliability of the scale. The consistence interval among research instrument items was passed. In reference to the alpha coefficient greater or equal to 0.5 , the research result proved to be valid and reliable. The Cronbach's alpha Coefficient was calculated to as:

\section{Data Analysis and Treatment}

Research questions were coded and entered and analyzed using Social Package for social sciences (SPSS) version 23, STATA 13 and MS Excel 2010 for quantitative data, for qualitative thematic interpretation will be used from direct quotations of the respondents.

These measures were used to describe the characteristics of the collected data. Inferential statistics will be used to determine the relationship and causal effects between the study variables. The primary association among the study variables will assessed using correlation analysis which will be tested at $95 \%$ confidence level (level of significance, $\alpha=0.05$ ). The hypothesis will be tested at two tailed with significant value of 0.05 .

\section{Research Findings}

\section{Competitiveness}

The study examines the organizational leadership as an important aspect of organizational competitiveness. It appreciates the influence of leaders and their leadership styles towards the overall performance of the organization. The hypothesis was tested by assessing the leadership styles in selected manufacturing organizations. The measurement focuses on leadership style vis-à-vis perceived organizational competitiveness.

The organizational leadership was one of the Independent variables to be studied. It was analyzed to determine the type of leadership style characterized by the selected medium and large manufacturing enterprises under the study. The objective of analysis was to establish its relationship with competitiveness. The four likert scale questionnaire was used to collect data for the analysis and the eight leadership styles (mainly Transactional, transformational, Bureaucratic, Autocratic, Charismatic, Laissez-faire, task oriented and democratic leadership styles) were assessed. The leadership variable was analyzed using four likert scale questionnaire whereby a total of sixteen questions were asked and answered by 85 respondents. The mean index was calculated and used to calculate the average mean index, based on which the significance level was determined. The descriptive analysis results are presented as per Table 1 below.

As indicated under table above, the results in the Table 1 show maximum figure of 4 represent strong agreement and Figure 1 to present minimum. This is based on the respondent's perceptions on rating the level of leadership among the surveyed companies.

The results shows that, enterprises posse's different leadership styles and with varying levels of practice. In general leadership style is predominantly at moderate level. The transactional leadership style has average mean index of (mean=2.1961); Transformational Leadership Style (mean=2.1029); Bureaucratic Leadership Style (mean=2.7059); Autocratic Leadership Style (mean $=2.753$ ); Charismatic Leadership style (mean=2.1882); Laissez-faire leadership style (mean=1.6882); Task Oriented Leadership Style $($ mean $=2.5176)$ and democratic Leadership Style (mean=2.1765). These statistical mean index figures indicates that, the significance of leadership in surveyed companies is at a moderate level (meaning that its neither bad nor good) with overall average mean index of $($ mean $=2.2910)$.

The leadership styles and levels varies from organization to organization, whereby autocratic, task oriented and bureaucratic leadership style are practiced most. The autocratic leadership style demonstrated by many of the organization gives clear indication as to how business show little concern of the employee's opinion and involvement in decision making. In return employees are less valued and probably not motivated or committed to perform their duties for competitiveness. In other words, leadership style has low stimuli towards competitiveness of manufacturing enterprises.

\section{Market orientation analysis results}

H02: Organizational Market orientation has a positive significant relationship on organizational competitiveness

The market orientation is considered as one of the key organizational factor with a positive relationship towards organizational competitiveness. The data was quantitative data was collected against seventeen questions structure under three constructs of: customer orientation, competitor and inter-functional. The objective of the analysis was to determine to what extent does each of the assed enterprises understands the value of MO and its relevance towards the organizational competitiveness. The three constructs under MO were assessed to see if respective enterprises are able to focus and satisfy its customers. The analysis results are presented under Table 2 below.

The results indicate that, the average mean index for Customer Orientation (MO) is (mean=2.1800), Competitor Orientation (1.9764) and Inter-Functional Coordination (mean=2.2627). The overall average mean index is at moderate level with the (mean=2.1397). This indicates that manufacturing organizations have weak performance in terms of market orientation. The companies hardly know their competitors, which makes it difficult for such enterprises to better define their competitive strategies and compete appropriately. The weak market orientation indicates that the production practices of 
Citation: Claude R (2018) Organizational Factors and Competitiveness: A Case Study of Medium and Large Manufacturing Enterprises in Rwanda. J Bus Fin Aff 7: 354. doi: 10.4172/2167-0234.1000354

Page 7 of 11

\begin{tabular}{|c|c|c|c|c|}
\hline \multicolumn{5}{|c|}{ Items list/Descriptive Statistics on Leadership Styles in sampled organizations } \\
\hline Transactional Leadership Style & Mean & Std. Deviation & Interpretation & Rank \\
\hline $\begin{array}{l}\text { 1. Leadership clarifies the work to be done, monitors and employees corrective measures to meet } \\
\text { acceptable standards }\end{array}$ & 2.2824 & 1.15069 & Moderate level & 8 \\
\hline 2. Leadership uses rewards and punishments to achieve performance & 1.8118 & 0.90625 & Moderate level & 14 \\
\hline 3. Leadership do not seek opinion of employees & 2.4941 & 1.15081 & Moderate level & 4 \\
\hline The average Mean Index 1 & 2.1961 & - & Moderate level & - \\
\hline Transformational Leadership Style & Mean & Std. Deviation & Interpretation & Rank \\
\hline 4. Leaders show empathy, support and keeps communication open & 2.3176 & 1.0714 & Moderate level & 6 \\
\hline 5. Leader mentors, motivates, coaches and involves employees in decision making & 2.2 & 1.07792 & Moderate level & 10 \\
\hline 6. Leadership encourages and stimulates innovation and creativity & 1.9412 & 1.18877 & Moderate level & 13 \\
\hline 7. Leaders walks the talk and imparts positive influence & 1.9529 & 1.11169 & Moderate level & 12 \\
\hline The average mean index 2 & 2.1029 & - & Moderate level & - \\
\hline Bureaucratic Leadership Style & Mean & Std. Deviation & Interpretation & Rank \\
\hline 8. Leadership is bureaucratic, and leaders acts as enforcers rather than a leader & 2.7059 & 0.93635 & High level & 2 \\
\hline Autocratic Leadership Style & Mean & Std. Deviation & Interpretation & Rank \\
\hline $\begin{array}{l}\text { 9. Leadership focuses on goal completion and shows little concern of the employee's opinion and } \\
\text { involvement in decision making }\end{array}$ & 3.13 & 0.753 & High level & 1 \\
\hline 10. Leadership makes decisions quickly and work is done efficiently & 2.3765 & 0.80143 & Moderate level & 5 \\
\hline Average Mean Index 4 & 2.753 & - & High level & \\
\hline Charismatic Leadership style & Mean & Std. Deviation & Interpretation & Rank \\
\hline 11. Leadership instill motivation, excitement and commitment among employees & 2.1882 & 1.0634 & Moderate level & 11 \\
\hline Laissez-faire leadership style & Mean & Std. Deviation & Interpretation & Rank \\
\hline 12. Employees are given complete control over their work and deadlines & 1.7294 & 0.99269 & Low level & 15 \\
\hline 13. Leaders are less involved, they just provide resources and advise as required & 1.6471 & 0.7974 & Lowe level & 16 \\
\hline Average Mean Index 6 & 1.68825 & - & Low level & \\
\hline Task Oriented Leadership Style & Mean & Std. Deviation & Interpretation & Rank \\
\hline 14. Leadership focuses on getting job done, monitors and organizes peoples work & 2.5176 & 0.82537 & High level & 3 \\
\hline Democratic Leadership Style & Mean & Std. Deviation & Interpretation & Rank \\
\hline 15. Leadership efficiently utilizes employee's skills and talents & 2.0471 & 1.1329 & Moderate & 9 \\
\hline 16. Leadership involves employees in decision making but the leader takes the final decisional & 2.3059 & 0.95148 & Moderate level & 7 \\
\hline The Average Mean Index 8 & 2.1765 & - & Moderate level & - \\
\hline The overall Average Mean Index & 2.291 & - & Moderate level & - \\
\hline
\end{tabular}

Source: Primary Data, 2016

Table 1: Leadership analysis.

manufacturing enterprises are probably not demand driven, resulting into less competitiveness of the organization.

\section{Organizational human resource analysis}

H03: Organizational HR has a positive significant relationship on organizational competitiveness

This study considered human resource as of the independent variable that is positively associated with organizational competitiveness. The Table 3 presents mean figures of respondents' opinion as regards to human resource capability of the organization.

The results indicated in Table 3 above, shows that human resource is at moderate level with average mean index of (mean=2.0704). This indicates that $\mathrm{HR}$ in all organizations is has weak contribution towards organizational competitiveness. In some cases, it was observed that, enterprises continue to recruit employees on relationship basis rather than competencies and there is little of HR planning, development and management. More so, enterprises rarely promote creativity and innovation for sustainability and enhanced ability to adapt to changing business environments and customer demands.

\section{Organizational asset tangibility analysis}

H04: Organizational asset tangibility has a positive significant relationship on organizational competitiveness
This variable measures asset worseness of a given assessed enterprises. The results are presented as per the Table 4 below.

The analysis result indicates that, many of the assessed organizations have assets. The $76.5 \%$ have buildings; $17.5 \%$ has land; $7.6 \%$ equipment and $1.2 \%$ with other assets such as vehicles. in terms of age of the equipment, $37.6 \%$ aged between $2-5$ years; $22.4 \%$ aged between $5-10$ years and $29.4 \%$ aged between $10-20$ years. The $29.4 \%$ gives an indication that competitiveness of such companies might be constrained by old their technological resource capacity. The equipment is old and requires replacement for competitiveness.

\section{Organizational financial resource analysis}

H1e: Organizational asset tangibility has a positive significant relationship on organizational competitiveness

This study considered financial resource as of the independent variable that is positively associated with organizational competitiveness. The Table 5 presents mean figures of respondents' opinion as regards to financial resource capability of the organization.

The results presented under the Table 5 above, indicates that the respondent's perceptions lie in the range of average mean index of (mean=2.4141) which is equivalent to moderate level. This shows that the financial capability possess moderate relationship towards organizational competitiveness. 
Citation: Claude R (2018) Organizational Factors and Competitiveness: A Case Study of Medium and Large Manufacturing Enterprises in Rwanda. J Bus Fin Aff 7: 354. doi: 10.4172/2167-0234.1000354

Page 8 of 11

\begin{tabular}{|c|c|c|c|c|}
\hline Customer Orientation (MO)_Constructs & Mean & Std. Deviation & Interpretation & Rank \\
\hline $\begin{array}{l}\text { 1. Customers are known and the information about them, is well communicated to all business functions } \\
\text { within the organization }\end{array}$ & 2.4824 & 0.95882 & Moderate level & 1 \\
\hline 2. Customer needs are well understood and forms the basis of organizational operations & 2.2941 & 1.06708 & Moderate level & 6 \\
\hline 3. Customer base has been growing over the last 3 years & 2.1765 & 1.13574 & Moderate level & 8 \\
\hline $\begin{array}{l}\text { 4. Customer expectations are regularly measured, communicated to employees and meet beyond } \\
\text { expectations }\end{array}$ & 2.0118 & 0.86594 & Moderate level & 11 \\
\hline $\begin{array}{l}\text { 5. Organizational Competitors and their competitive advantage are well known and forms the basis for } \\
\text { continuous improvement programme design of the organization }\end{array}$ & 2.2118 & 0.98916 & Moderate level & 7 \\
\hline 6. Competitive strategy regularly reviewed for competitiveness & 1.9765 & 1.09083 & Moderate level & 12 \\
\hline 7. Enough budget is dedicated to marketing and communication function & 2.3176 & 1.10423 & Moderate level & 4 \\
\hline 8. Individuals in production department interact directly with customers to learn how to serve them better & 1.7647 & 0.95925 & Moderate level & 17 \\
\hline 9. Organization timely adapts to the market and customer needs & 2.1529 & 0.9064 & Moderate level & 9 \\
\hline 10. Organization offers new and innovative products and services in a dynamic manner & 2.4118 & 0.9167 & Moderate level & 2 \\
\hline The average Mean Index & 2.18 & - & Moderate level & - \\
\hline Competitor Orientation Constructs & Mean & Std. Deviation & Interpretation & Rank \\
\hline $\begin{array}{l}\text { 11. Information regarding competitors' action is regularly collected and discussed to inform the formulation } \\
\text { of new strategies }\end{array}$ & 1.9412 & 1.18877 & Moderate level & 14 \\
\hline 12. Competitors strategies and capabilities identified and understood & 2.0941 & 1.09787 & Moderate level & 13 \\
\hline 13. Competitors' current and feature is well predicated & 1.9294 & 1.05546 & Moderate level & 16 \\
\hline 14. Market research is regularly undertaken within the organization & 1.9412 & 0.89113 & Moderate level & 15 \\
\hline The average mean Index 2 & 1.9764 & - & Moderate level & - \\
\hline Inter-Functional Coordination & Mean & Std. Deviation & Interpretation & Rank \\
\hline 15. Efforts and resources are well coordinated in the organization to create superior value for customers & 2.3059 & 1.0468 & Moderate level & 5 \\
\hline 16. Departments work closely together for improvement & 2.3765 & 1.04627 & Moderate level & 3 \\
\hline 17. Market information is disseminated vertically and horizontally within the organization & 2.1059 & 1.02381 & Moderate level & 10 \\
\hline The average Mean Index 3 & 2.2627 & - & $\begin{array}{l}\text { Moderate } \\
\text { level }\end{array}$ & - \\
\hline The Overall Average Mean Index & 2.1397 & - & $\begin{array}{l}\text { Moderate } \\
\text { level }\end{array}$ & - \\
\hline
\end{tabular}

Table 2: Market orientation variable analysis results.

\begin{tabular}{|c|c|c|c|c|}
\hline Statement & Mean & Std. Deviation & Interpretation & Rank \\
\hline 1. Organization has effective HR planning and utilization & 2.1667 & 1.03939 & Moderate level & 4 \\
\hline 2. HR plan fully aligns with the organizational goals and strategy & 2.1310 & .92853 & Moderate level & 5 \\
\hline $\begin{array}{l}\text { 3. HR systems are effectively built and enables the organization to effectively identify, recruit, } \\
\text { select, orientate and place the right employees for the right job }\end{array}$ & 1.7738 & 10.07939 & Moderate level & 10 \\
\hline 4. HR Measures - used to 'hedge' talented and critical skilled employees from leaving the enterprise & 1.8571 & 0.83800 & Moderate level & 8 \\
\hline 5. Employees are well experienced, motivated, happy, skilled, creative and innovative & 1.9881 & 0.96310 & Moderate level & 6 \\
\hline 6. In-house skills and competencies are well aligned with work & 1.7857 & 0.91929 & Moderate level & 9 \\
\hline 7. Employees are recruited on relationship rather than on competency basis & 3.0833 & 1.08892 & High level & 1 \\
\hline $\begin{array}{l}\text { 8. Managers and workers are trained on regular basis, impact of training is regularly measured, } \\
\text { and employees have positive attitude towards work }\end{array}$ & 1.6667 & 0.84073 & Low level & 12 \\
\hline 9. Employees work under pressure, stressed and overloaded with work & 2.5952 & 0.94575 & High level & 2 \\
\hline 10. Organization a wards Talent, creativity and Innovation & 1.7024 & 0.91546 & Low level & 11 \\
\hline 11. Employee behaviors, skills, productivity and performance is measured for efficiency & 1.9048 & 0.96467 & Moderate level & 7 \\
\hline 12. The organization develops and fosters the professionalism of managers and workers & 2.1905 & 0.93752 & Moderate level & 3 \\
\hline The Average Mean Index & 2.0704 & - & Moderate level & - \\
\hline
\end{tabular}

Table 3: Human resource analysis results.

\section{Relationship and causal effect analysis}

The correlational and regression analysis results are presented as per the Tables $6-8$ below respectively.

The relationship analysis research design method was used to assess the significance level of each variable. The Table 7 results indicate that organizational factors were positively correlated with organizational competitiveness. It evident that, the leadership has weak relationship with competitiveness ( $r$-value $=0.051$ and $P$-value of $0.646>0.05$ ). The research findings conclude that leadership insignificantly to organizational competitiveness.

Market orientation has a significant relationship with organizational competitiveness with correlation coefficient ( $r$-value $=0.425$ with $\mathrm{P}$-value of 0.000 ). The results indicate that, market orientation has significant level of effects towards organizational competitiveness than leadership.

The Human resources is correlated with organizational competitiveness at weak level of ( $r$-value $=0.199$ and P-value of 0.068 which is greater than 0.05) this indicated that human resource has a little influence on competitiveness. The asset tangibility is also correlated with competitiveness with ( $r$-value $=0.252$ with sign-value 0.02 which is less than 0.05 ). This indicates that the asset tangibility is broadminded that it contributes to competitiveness at certain level.

The financial resources capability is correlated with organizational 
Citation: Claude R (2018) Organizational Factors and Competitiveness: A Case Study of Medium and Large Manufacturing Enterprises in Rwanda. J Bus Fin Aff 7: 354. doi: 10.4172/2167-0234.1000354

Page 9 of 11

\begin{tabular}{|c|c|c|}
\hline Fixed Asset & Count Resp. & $\%$ Share Resp. \\
\hline Buildings & 65 & 76.5 \\
\hline Land & 15 & 17.6 \\
\hline Equipment & 4 & 7.6 \\
\hline Others & 1 & 1.2 \\
\hline Total & 85 & 100 \\
\hline The average age of capital equipment used in production & Count Resp. & $\%$ Share Resp. \\
\hline $2-5$ years & 32 & 37.6 \\
\hline $5-10$ years & 19 & 22.4 \\
\hline $10-20$ years & 25 & 29.4 \\
\hline Other & 8 & 9.4 \\
\hline Not Stated & 1 & 1.2 \\
\hline Total & 85 & 100 \\
\hline
\end{tabular}

Source: Primary data, 2016

Table 4: Type of assets.

\begin{tabular}{|c|c|c|c|c|}
\hline Statements & Mean & Std. Deviation & Interpretation & Rank \\
\hline \multicolumn{5}{|c|}{ Financial Resource Analysis } \\
\hline 1. The organization is adequately financially resourced & 2.0000 & 1.15470 & Moderate level & 6 \\
\hline 2. The organization has efficient financial management systems & 2.5696 & .98298 & High level & 2 \\
\hline 3. Financial resources are effectively and efficiently mobilized and utilized & 2.1519 & .98825 & Moderate level & 5 \\
\hline 4. Employees are effectively involved in planning and budgeting & 2.3671 & 1.00227 & Moderate level & 4 \\
\hline 5. The organization has tools for financial planning, control, measurement and reporting & 2.4051 & 1.18234 & Moderate level & 3 \\
\hline $\begin{array}{l}\text { 6. The organization is aware of its financial statutory and compliance requirements and } \\
\text { its compliant }\end{array}$ & 3.5949 & .51934 & Very high level & 1 \\
\hline 7. Does the Average retained earnings increase over the past three years & 1.8101 & 1.20975 & Moderate level & 7 \\
\hline The average Mean index & 2.4141 & - & Moderate level & - \\
\hline
\end{tabular}

Table 5: Organizational financial Resource analysis.

\begin{tabular}{|c|c|c|c|c|c|c|c|}
\hline & & Leadership & $\begin{array}{c}\text { Market } \\
\text { Orientation }\end{array}$ & $\begin{array}{c}\text { Human } \\
\text { Resources }\end{array}$ & $\begin{array}{c}\text { Assets } \\
\text { Tangibility }\end{array}$ & $\begin{array}{c}\text { Financial Resources } \\
\text { Capability }\end{array}$ & $\begin{array}{l}\text { Organizational } \\
\text { Competitiveness }\end{array}$ \\
\hline \multirow{3}{*}{ Leadership } & Pearson Correlation & 1 & 0.166 & -0.031 & -0.004 & 0.169 & 0.051 \\
\hline & Sig. (2-tailed) & & 0.129 & 0.781 & 0.972 & 0.122 & 0.646 \\
\hline & $\mathrm{N}$ & 85 & 85 & 85 & 85 & 85 & 85 \\
\hline \multirow{3}{*}{ Market Orientation } & Pearson Correlation & 0.166 & 1 & $0.423^{\star \star}$ & $0.585^{\star \star}$ & $0.460^{\star *}$ & $0.425^{\star *}$ \\
\hline & Sig. (2-tailed) & 0.129 & & 0 & 0 & 0 & 0 \\
\hline & $\mathrm{N}$ & 85 & 85 & 85 & 85 & 85 & 85 \\
\hline \multirow{3}{*}{ Human Resources } & Pearson Correlation & -0.031 & $0.423^{* *}$ & 1 & $0.492^{* *}$ & $0.447^{* *}$ & 0.199 \\
\hline & Sig. (2-tailed) & 0.781 & 0 & & 0 & 0 & 0.068 \\
\hline & $\mathrm{N}$ & 85 & 85 & 85 & 85 & 85 & 85 \\
\hline \multirow{3}{*}{ Assets Tangibility } & Pearson Correlation & -0.004 & $0.585^{\star *}$ & $0.492^{* *}$ & 1 & $0.676^{* *}$ & $0.253^{*}$ \\
\hline & Sig. (2-tailed) & 0.972 & 0 & 0 & & 0 & 0.02 \\
\hline & $\mathrm{N}$ & 85 & 85 & 85 & 85 & 85 & 85 \\
\hline \multirow{3}{*}{$\begin{array}{c}\text { Financial Resources } \\
\text { Capability }\end{array}$} & Pearson Correlation & 0.169 & $0.460^{* *}$ & $0.447^{* *}$ & $0.676^{\star *}$ & 1 & 0.198 \\
\hline & Sig. (2-tailed) & 0.122 & 0 & 0 & 0 & & 0.069 \\
\hline & $\mathrm{N}$ & 85 & 85 & 85 & 85 & 85 & 85 \\
\hline \multirow{3}{*}{$\begin{array}{l}\text { Organizational } \\
\text { Competitiveness }\end{array}$} & Pearson Correlation & 0.051 & $0.425^{\star *}$ & 0.199 & $0.253^{*}$ & 0.198 & 1 \\
\hline & Sig. (2-tailed) & 0.646 & 0 & 0.068 & 0.02 & 0.069 & \\
\hline & $\mathrm{N}$ & 85 & 85 & 85 & 85 & 85 & 85 \\
\hline
\end{tabular}

${ }^{* *}$ Correlation is significant at the 0.01 level (2-tailed)

${ }^{* *}$ Correlation is significant at the 0.05 level (2-tailed)

Table 6: Correlational matrix of variables.

competitiveness at weak level of ( $r$-value $=0.196$ with significant value of 0.072 which is greater than 0.05 ) this indicated that the financial resources capability has a little influence on competitiveness.

According to the regression analysis results in the above table, the variables included in the model account for $13 \%$ variations independent variable, indicated by low adjusted $r$-square of 0.13 (13\%). The Results indicates that the independent variable included in the model significantly affect the dependent variable (competitiveness) with $\beta=3.4846$ and $P$-value of 0.006 ). The coefficients tables indicate the contribution of each independent variable to dependent where by leadership has ( $\beta=0.51$ and $\mathrm{P}$-value of 0.86 ); Market orientation ( $\beta=0.425$, P-value of 0.002$)$; Human resource $(\beta=0.199$, $p$-value of $0.851)$; Asset tangibility $(\beta=0.0252$, $\mathrm{P}$-value of 0.970$)$ and Financial Resources capability ( $\beta=0.196$, and P-value of 0.995$)$. 


\begin{tabular}{|c|c|c|c|c|}
\hline Independent variables & r-value & P-value & Interpretation & Decision on Hypothesis \\
\hline Level of leadership & $r_{1}=0.051$ & 0.646 & No significant correlation & H01: Rejected \\
\hline Level of Market Orientation & $r_{1=}=0.42$ & 0.000 & Significant correlation & H02: Accepted \\
\hline Level of Human Resource & $r_{1}=0.199$ & 0.068 & No Significant correlation & H03: Rejected \\
\hline Level of Assets tangibility & $r_{1}=0.252$ & 0.020 & Significant correlation & H04: accepted \\
\hline Level of financial resources capability & $r_{1}=0.196$ & 0.072 & No Significant correlation & H05: Rejected \\
\hline
\end{tabular}

Source: primary data, 2016

Table 7: Summery of correlation analysis results.

\begin{tabular}{|c|c|c|c|c|c|}
\hline Variables Correlated & Adjusted $r^{2}$ & Fisher- value & P-Value & Interpretation & Decision on Hypothesis \\
\hline Organizational factors Vs competitiveness & 0.13 & 3.509 & 0.006 & Significant effect & Overall Hypothesis Accepted \\
\hline Coefficients & Beta & t-value & Sig. & Interpretation & Decision on Ho \\
\hline (Constant) & 3.4846 & 3.588 & 0.001 & Significant effect & Accepted \\
\hline Leadership (L) & 0.51 & 0.176 & 0.860 & No Significant effect & H01: Rejected \\
\hline Market orientation (MO) & 0.425 & 3.220 & 0.002 & Significant effect & H02: Accepted \\
\hline Human Resources (HR) & 0.199 & 0.188 & 0.851 & No Significant effect & H03: Rejected \\
\hline Assets Tangibility (AT) & 0.0252 & 0.037 & 0.970 & No Significant effect & H04: Rejected \\
\hline Financial resource capability (FRC) & 0.196 & 0.007 & 0.995 & No Significant effect & H05: Rejected \\
\hline
\end{tabular}

Summary model: $Y=\beta O+\beta 1 \times 1+\beta 2 \times 2+\beta 3 \times 3+\beta 4 \times 4+\beta 5 \times 5+\mu=O C=3.4846+0.51 L+0.425 \mathrm{M}+0.199 \mathrm{HR}+0.0252 \mathrm{AT}+0.196 \mathrm{FRC}+14122$

Source: primary data, 2016

Table 8: Regression analysis results.

These results indicate that all variables that have the sign- values which are greater than degree of precision of 0.05 , which means that they have insignificant influence on competitiveness. Only market orientation indicated significant effect with $\mathrm{P}$-value of $0.002<0.05$ towards competitiveness.

\section{Conclusion}

The general objective of this study was to investigate the relationship between organizational factors and competitiveness. The adjusted $r^{2}$ of 0.13 of the regression analysis results concluded that organizational factors have positive relationship with organizational competitiveness. In respect to specific objectives of the study, the analysis results indicated that, many of the independent variables have the P-values which are greater than degree of precision of 0.05 , they have insignificant influence on competitiveness. However, the asset tangibility $\left(r_{1}=0.020\right)$ and Market orientation $\left(r_{1}=0.000\right)$ independent variables proved to have a significant relationship towards dependent variable (competitiveness). Also, the regression analysis results revealed that MO has $\mathrm{r}^{2}$ of 0.425 and $\mathrm{P}-\mathrm{V}$ alue of 0.002 , thus this variable presented significant effect to organizational competitiveness.

The study hypothesized that organizational factors have a significant positive effect on organizational competitiveness. The qualitative and quantitative research designs were used to test the hypothesis. The hypothesis tested positive. The respondents agree that organizational factors such as leadership, asset tangibility, human resource, financial and market orientation capability of the organization have a positive effect towards organizational competitiveness. Qualitatively, the $65.9 \%$ of the assessed manufacturing enterprises agree that there are not competitive. The correlational analysis results revealed that organizational factors have moderately positive effect towards organizational competitiveness. The results concur with the findings of Alimin and Wilfred. The regression analysis results concluded that market orientation $(\mathrm{P}$-value $0.002<0.05)$ has a significant positive effect towards organizational competitiveness while other variables did not.

\section{Recommendations}

On the basis of relationship and causal effect analysis results, the following recommendations have been proposed for the consideration of policy makers, enterprises and future researchers:

- Given that the average mean index of each variable was ranked moderate, policy makers need to re-assess the capacity gaps of business leaders and business managers to develop appropriate capacity building to enhance competitiveness.

- The business leaders need to focus and promote staff motivation, creativity and innovation for better performance because the leaders are autocratic and show little involvement of employees.

- Enterprise business leaders should recruit employees on competency basis rather than relationship

- Enterprises should award employees' talents, creativity and innovation to increase the quality of production and be able to adapt to the changing market needs.

- The future researchers should carry on the same topic using different independent variables that were not analyzed. These variables should include intangible organizational resources, market factors and other environmental factors.

\section{References}

1. UN (2011) Economic Development in Africa Report: Fostering industrial development in Africa in the new global Environment.

2. Diabate A (2014) Factors Influencing Small and Medium Enterprises (SMEs) in Adoption and Use of Technology in Cote d'Ivoire. Int J Bus Manag 9: 179-190.

3. Boonthawan W (2012) Effects of Entrepreneurship, Organization Capability, Strategic Decision Making and Innovation toward the Competitive Advantage of SMEs Enterprises. J Manag Sustain 2: 137-150.

4. Thorsten B, Demirguc-Kunt A (2006) Small and medium-size enterprises: Access to finance as a growth constraint. J Bank Financ 30: 2931-2943.

5. Sophia K, Soderbom M (2013) Constraints and Opportunities in Rwanda's Industrial Sector online International Growth Centre.

6. Kaberuka D (2000) Rwanda Vision 2020. Ministry of Finance and Economic Planning. 
Citation: Claude R (2018) Organizational Factors and Competitiveness: A Case Study of Medium and Large Manufacturing Enterprises in Rwanda. J Bus Fin Aff 7: 354. doi: 10.4172/2167-0234.1000354

Page 11 of 11

7. NISR (2015a) Establishment Census Report of 2014. National Institute of Statics of Rwanda.

8. NISR (2015c) Gross Domestic Product quarter 3 report. National Institute of Statistics of Rwanda.

9. NISR (2015d) Rwanda Integrated household living conditions survey of 2013/2014. National Institute of statistics of Rwanda.

10. NISR (2015b) Formal external trade in goods statistics report (Q2). Nationa Institute of statistics of Rwanda (NISR).

11. Schwab K (2013) The global competitiveness report 2013-2014. WEF.

12. UNIDO (2007) Building linkages for competitive and responsible entrepreneurship.

13. UN (2013) Rwanda United Nations Development Assistance Plan of 20132018. United Nations Rwanda.

14. EAC (2012) The East African Community Industrialization Strategy 2012-2032. East African Community (EAC).

15. Manju P, Sharma B (2015) A Comprehensive review of factors influencing HRM practices in manufacturing industries. J Manage Eng Inf Technol 2: 21-29.

16. Asta S, Masteikiene R, Venckuviene V (2014) Exogenous factors of the textilerelated low-tech industries competitiveness in Lithuania. Procedia-Social and Behavioral Sciences 156: 298-303.

17. Daša D (2013) Impact of Internal and External Factors on the Performance of Fast-Growing Small and Medium Businesses. J Contemp Manag 19: 119-159.

18. Wilfred NM, Matoke J, Yegon R, Egessa R (2014) Moderating effect of Organizational Factors on the relationship between Diversification Strategies and Competitiveness: Case of Sugar Firms in Kenya. Eur J Bus Manag.

19. Julian PS (2014) Organizational Factors and Quality of Production in Malaysia's Manufacturing Companies. Int J Bus Manag 9: 1-9

20. György K (2006) Research of Competitiveness Factors of SME. Acta Polytechnica Hungarica 3: 71-84.

21. Houshang M, Babakhanianb M (2015) World Conference on Technology, Innovation and Entrepreneurship: Identification of Factors Affecting Organizational Entrepreneurship in Selected Sama Technical Schools. Procedia - Social and Behavioral Sciences 195: 940-947.

22. Martins EC, Martins N (2011) The role of organizational factors in combating tacit knowledge loss in organizations. S Afr Bus Rev 15: 49-69.

23. Yosuke K, Shibata S (2013) Organizational Factors in the Product Design Development Process. Int J Bus Manage 8: 15-26.

24. Alvarenga MAB, Frutuoso e Melo PF, Fonseca RA (2014) A critical review of methods and models for evaluating organizational factors in Human Reliability Analysis. Progress in Nuclear Energy 75: 25-41.

25. Hessam S, Libaers D, Burkemper A (2015) Examining the relationship between creativity and innovation: A meta-analysis of organizational, cultural, and environmental factors. J Bus Venturing 30: 714-731.

26. Sadegh R, Senin AA, Tourani A (2015) Effect of Organizational Factors on University-Industry Collaboration: A Conceptual Model. Int J Bus Manag.
27. Rukevwe OJ (2015) Effect of Innovation on the Performance of SMEs Organizations in Nigeria. Management 5: 90-95.

28. Carlos J, Gonzalez-Loureiro M (2013) Human Capital as Source for Sustained Competitive Advantages in SMEs: A Core Competencies Approach. Economia Seria Management 16: 255-276.

29. Anita LT, Heisler WS, Janisse LD (2013) Organizational Factors that Contribute to Operational Failures in Hospitals.

30. Chee-Hua C, Lo MC, Ramayah T (2013) Market Orientation and Organizationa Performance: The Moderating Role of Service Quality. SAGE Open 3: 1-14.

31. Nachiappan S, Gunasekaran A, Yu J, Ning K (2014) Customer satisfaction and competitiveness in the Chinese E-retailing: Structural equation modeling (SEM) approach to identify the role of quality factors. Expert Systems with Applications 41: $69-80$.

32. Razvan V, Moisoiu C (2015) Competitiveness, Theoretical and Policy Approaches. Towards a more competitive EU. Procedia Economics and Finance 22: 512-521.

33. Salvador $P$, Rodríguez MB, Luque M (2015) Assessing global competitiveness under multi-criteria perspective. Economic Modelling.

34. Chiang K, Wu WY, Hsieh WJ, Chen LH (2008) Measuring the national competitiveness of Southeast Asian countries. Eur J Oper Res 187: 613-628.

35. Díaz-chao A, Sainz-González J, Torrent-Sellens J (2015) The competitiveness of small network-firm: A practical tool. J Bus Res 69: 1769-1774.

36. Hughes GC (2006) Organizational Leadership and Change Mgt. (5th ed) McGraw-Hill Companies. Inc., USA

37. Gerry J, Scholes K, Richard W (2008) Exploring Corporate strategy England.

38. Sarah S (2012) The Styles, Models \& Philosophy of Leadership.

39. Yanney JP (2014) Business strategy and leadership style: Impact on organizational performance in the manufacturing sector of Ghana. Am J Ind Bus Manage 4: 767-775

40. Haim HA, Kaliappen N (2014) Market Orientation Practices and Effects on Organizational Performance: Empirical Insight from Malaysian Hotel Industry. SAGE Open pp: 1-8.

41. Qiang W, Zhao X, Voss C (2016) Customer orientation and innovation: A comparative study of manufacturing and service firms. Int J Prod Econ 171 221-230.

42. Joyce MWL, Kwon LB (2014) Effects of internal resources on airline competitiveness. J Air Transp Manag 36: 23-32.

43. Alimin II, Rose CR, Jegak U, Haslinda A (2012) The relationship between organizational resources, capabilities, systems and competitive advantage. Asian Acad Manage 17: 151-173.

44. Vanessa CC, Joan-Ramon SP (2015) How much does size matter in agri-food firms? J Bus Res 68: 1589-1591.

45. Dong-Hyeon K, Shu-Chin L, Ting-Cih C, Lin SC (2016) Financial structure, firm size and industry growth. Int Rev Econ Finance 41: 23-39.

46. Frankfort-Nadunias CND (1996) Research Methods in the bcial Sciences., New Yak SI. Martin's Press. 